\title{
IHC desplugada e a sala de aula criativa
}

\author{
Milene Selbach Silveira \\ Escola Politécnica \\ Pontifícia Universidade Católica do Rio Grande do Sul \\ Porto Alegre - RS - Brasil \\ milene.silveira@pucrs.br
}

\section{RESUMO}

A busca pelo engajamento e protagonismo do aluno, em prol do desenvolvimento das competências necessárias para sua atuação em um mercado em constante evolução, traz a discussão constante pela inovação em sala de aula. Mais (ou menos) que inovação em sala de aula, este minicurso busca, por meio de atividades desplugadas, fomentar um maior envolvimento do aluno nas atividades de aula, com sua participação em práticas que promovem a colaboração e a criatividade.

\section{Palavras chave}

Unplugged CS, sala de aula criativa, protagonismo do aluno

\section{APRESENTAÇÃO}

A evolução do mercado e a necessidade de formar profissionais que estejam aptos a suas constantes mudanças é um desafio para a educação profissional e superior. Em Filatro e Cavalcanti [6] são discutidas algumas competências fundamentais que devem ser desenvolvidas para se estar qualificado para atuar neste mundo incerto e desafiador: a colaboração, a solução de problemas, a curiosidade e imaginação, e o pensamento crítico, dentre outras.

Para desenvolver estas competências e, também, para fomentar o engajamento do aluno em prol de uma aprendizagem mais significativa, professores tem experimentado diferentes estratégias.

O uso de metodologias (inov)ativas tem sido alvo de diversas publicações [2][5][6][8] e é um tópico quase onipresente em fóruns atuais relacionados ao ensino. Tendo, como princípios essenciais, o protagonismo do aluno, a ação-reflexão e a colaboração [6], são discutidas abordagens como a sala de aula invertida, a avaliação por pares, a aprendizagem baseada em problemas e em projetos, os jogos e a gamificação, dentre outras.

Em se tratando de Computação, um movimento que tem se destacado é a computação desplugada (unplugged Computer

Permission to reproduce or distribute, in whole or in part, material extracted from this work, verbatim, adapted or remixed, as well as the creation or production from the content of such work, is granted without fee for non-commercial use, provided that the original work is properly credited.

IHC 2019 - Minicursos, Outubro 21-25, 2019, Vitória, Brasil. In Anais Estendidos do XVIII Simpósio Brasileiro sobre Fatores Humanos em Sistemas

Computacionais. Porto Alegre: SBC.

(C) 2019 by the author(s), in accordance with the terms of the Creative Commons Attribution-NonCommercial 4.0 International Public License (CC BY-NC 4.0).
Science) ${ }^{1}$ [3][4]. O objetivo principal deste movimento é promover a área para jovens como uma disciplina interessante, engajadora e intelectualmente estimulante. E, dentre seus principais princípios ${ }^{2}$, vemos também o estímulo ao aprender fazendo, a diversão, a inclusão e a cooperação, princípios estes que promovem um maior envolvimento dos participantes.

Se focarmos especificamente na área de Interação HumanoComputador (IHC), no livro original de Bell, Witten e Fellow [3] sobre computação desplugada, temos uma atividade específica para o tema (Activity 19 - The chocolate factory-Human interface design), a qual, inclusive, já foi instanciada para o cenário brasileiro [1][7]. Outra atividade interessante pode ser vista em um vídeo postado no canal de YouTube da comunidade unplugged, que trata do efeito stroop [10]. Esta é uma atividade bastante rápida de ser executada em sala de aula, bem em linha com as miniatividades para trabalhar conceitos básicos de IHC, propostas por Pontual Falcão [9].

Neste cenário de busca por uma maior participação e protagonismo por parte do aluno, com inspiração no engajamento propiciado pelas atividades desplugadas e numa perspectiva de construção aliada à diversão, neste minicurso serão apresentadas e discutidas algumas atividades que têm sido utilizadas - sem uso do computador - em disciplinas de IHC nos últimos anos. E, para se melhor compreender o objetivo e as possibilidades deste tipo de atividades, algumas delas serão tanto experimentadas quanto criadas pelos participantes durante o minicurso.

As seções a seguir descrevem em maior detalhe o minicurso proposto, com a apresentação das atividades pretendidas, do público esperado, da duração pretendida, do idioma no qual será ministrado, dos materiais necessários, bem como a apresentação de uma biografia resumida da proponente.

\section{SUMÁRIO ESTENDIDO}

O minicurso prevê quatro etapas:

- Introdução (30 min): apresentação dos participantes e discussão sobre ensino de IHC, metodologias ativas e computação desplugada.

- Casos reais (1 hora): apresentação e discussão de exemplos práticos trabalhados pela ministrante em sala

\footnotetext{
${ }^{1}$ https://csunplugged.org/en/

2 https://csunplugged.org/en/principles/
} 
de aula, em disciplinas de IHC oferecidas tanto em cursos de graduação quanto de pós-graduação. Serão apresentados exemplos de atividades que utilizam materiais diversificados, como massa de modelar e elementos de jogos de tabuleiro, além de exemplos de pequenas atividades práticas variadas relacionadas a diferentes tópicos/conceitos. Todas as atividades serão contextualizadas com as possibilidades de conceitos e habilidades a serem trabalhados, com os diferentes materiais que podem ser utilizados, além de exemplos de como foram trabalhadas nas diferentes disciplinas de IHC (e com diferentes tamanhos de turmas, desde as mais reduzidas, com cerca de 12 a 15 alunos, às mais populosas, com cerca de 50 alunos). Para algumas das atividades serão discutidas, também, percepções dos alunos sobre sua realização. Além da apresentação e discussão dos casos reais, uma versão reduzida da atividade com uso de massa de modelar - que trabalha o processo de design, com destaque aos diferentes papéis envolvidos, à importância da participação do usuário, e o conceito de iteratividade - será vivenciada na prática.

- Mãos na massa (1 hora): momento para os participantes colocarem em prática o que foi discutido até o momento. $\mathrm{O}$ grupo de participantes será dividido em pequenas equipes, com objetivo de criar - cada uma - um jogo de tabuleiro tratando de algum tema específico de IHC. Como apoio ao trabalho, além do conhecimento e experiência dos participantes sobre o tema escolhido e os diferentes contextos de ensino aos quais os participantes estão inseridos, serão utilizados diferentes materiais (elementos de jogos e exemplos de tabuleiros) a serem fornecidos pela ministrante.

- Discussão final (30 $\mathrm{min})$ : como última etapa, está prevista a apresentação das atividades criadas pelos diferentes grupos, com uma discussão sobre as possibilidades de uso deste tipo de atividades, dificuldades e desafios neste contexto.

\section{PÚBLICO-ALVO}

O minicurso é destinado inicialmente a professores, mas tanto alunos de graduação e de pós-graduação quanto profissionais que se interessem pelo tema são bem-vindos. As atividades apresentadas terão como foco a área de IHC, mas também podem ser aplicadas a outros contextos de ensino ou de trabalho.

\section{DURAÇÃO DO MINICURSO}

O minicurso está previsto para duração de três horas, com duas etapas de 30 min e duas de 1 hora, conforme descrito no sumário estendido apresentado na seção 2 .

\section{IDIOMA EM QUE SERÁ MINISTRADO}

O minicurso será ministrado em português.

\section{INFRAESTRUTURA E MATERIAIS}

Para realização do minicurso, são necessários: um computador e projetor (para projeção dos slides da ministrante), sala com mesas (e/ou cadeiras) que possam ser dispostas de forma a permitir trabalho em grupos, folhas A3 e canetas. Os demais materiais necessários serão levados pela ministrante.

\section{BIOGRAFIA DO AUTOR}

Milene Silveira é Mestre em Computação pela UFRGS (1996) e Doutor na mesma área pela PUC-Rio (2002). É professora da PUCRS desde 1994, atuando na área de Interação HumanoComputador (IHC) e suas aplicações e relações com desenvolvimento por usuário final, visualização de dados, métodos ágeis, objetos de aprendizagem e ensino de IHC. Especificamente em relação ao ensino de IHC, a proponente organizou o primeiro grupo de trabalho sobre currículos de IHC no IHC2006, diversos dos Workshops sobre Educação em IHC (WEIHC) ocorridos ao longo dos últimos anos, além de ter várias publicações sobre o tema, em conjunto com colegas da comunidade nacional de IHC.

\section{REFERÊNCIAS}

[1] M.A. Amaral, S.A. Bim, C. Boscarioli e C. Maciel. 2015. Introducing Computer Science to Brazilian Girls in Elementary School Through HCI Concepts. Em: A. Marcus (eds) Design, User Experience, and Usability: Users and Interactions. DUXU 2015. Lecture Notes in Computer Science, vol 9187. Springer, Cham, Suíça.

[2] L. Bacich e J. Moran. 2018. Metodologias ativas para uma educação inovadora: uma abordagem teórico-prática. Penso, Porto Alegre, RS, Brasil.

[3] T. Bell, I.H. Witten e M. Fellows. 1999. Computer Science Unplugged: OffLine Activities and Games for All Ages (Original Book). http://csunplugged.org

[4] T. Bell e J. Vahrenhold. 2018. CS Unplugged-How Is It Used, and Does It Work? Em: HJ. Böckenhauer, D. Komm and W. Unger W. (eds) Adventures Between Lower Bounds and Higher Altitudes. Lecture Notes in Computer Science, vol 11011. Springer, Cham, Suíça.

[5] F. Camargo e T. Daros. 2018. A sala de aula inovadora: estratégias pedagógicas para fomentar o aprendizado ativo. Penso, Porto Alegre, RS, Brasil.

[6] A. Filatro e C.C. Cavalcanti. 2018. Metodologias Inov-ativas na educação presencial, a distância e corporativa. Saraiva Educação, São Paulo, SP, Brasil.

[7] C. Maciel, S.A. Bim e C. Boscarioli. 2013. HCI with Chocolate: Introducing HCI Concepts to Brazilian Girls in Elementary School. In: Collazos C., Liborio A., Rusu C. (eds) Human Computer Interaction. CLIHC 2013. Lecture Notes in Computer Science, vol 8278. Springer, Cham, Suiça.

[8] J. Mattar. 2017. Metodologias ativas: para educação presencial, blended e a distância. Artesanato Educacional, São Paulo, SP, Brasil.

[9] T. Pontual Falcão. 2018. Miniatividades sobre conceitos básicos de IHC: dinamizando aulas expositivas. Workshop sobre Educação em IHC, XVII Simpósio Brasileiro sobre Fatores Humanos em Sistemas Computacionais IHC 2018. SBC, Porto Alegre, RS, Brasil.

[10] UC Computer Science. Education Unplugged: The show. Part 6: HCI - The Stroop effect. https://www.youtube.com/watch?v=4iHPgk2u9_s 